\title{
De normalistas a bancárias: Caminhos da profissionalização das mulheres no sul do Brasil (1960-1980)
}

Carlos Geroleti, Luciana

Universidade Federal de Santa Catarina, Brasil

geroleti@gmail.com

Cita sugerida: Carlos Geroleti, L.(2018). De normalistas a bancárias: Caminhos da profissionalização das mulheres no sul do Brasil (1960-1980) Anuario del Instituto de Historia Argentina, 18 (1), e065. https://doi.org/10.24215/2314-257Xe065

Recibido: 16 Fevereiro 2018 - Aceptado: 08 Maio 2018 - Publicado: 28 de junio de 2018 


\title{
De normalistas a bancárias: Caminhos da profissionalização das mulheres no sul do Brasil (1960-1980)
}

From Normal to Banking: Pathways to the professionalization of women in southern Brazil (1960-1980)

Luciana Carlos Geroleti

Universidade Federal de Santa Catarina, Brasil

geroleti@gmail.com

\section{Resumo:}

O presente artigo, resultante de Mestrado em História, trata dos caminhos percorridos por cinco mulheres em duas profissões: a normalista e a bancária. Utilizando a metodologia da História Oral, a pesquisa teve como fonte entrevistas com mulheres que trocaram a profissão de professora pela carreira em bancos públicos entre as décadas de 1960 e 1980. Como se concluiu, a mudança de profissão fez parte de um processo histórico mais amplo que levou muitas mulheres das classes médias no Brasil ao mercado de trabalho, revelando permanências no tocante às tradicionais ocupações femininas.

Palavras-Chave: Mulheres, Profissionalização, Normalistas, Bancárias.

\begin{abstract}
:
This article, resulting from a Masters in History, deals with the paths traveled by five women in two professions: the normalist and the banking. Using the Oral History methodology, the research was based on interviews with women who changed the profession of teacher for a career in public banks between the 1960s and 1980s. As it turned out, the change of profession was part of a broader historical process which led many women from the middle classes in Brazil to the labor market, revealing permanences regarding the traditional female occupations.
\end{abstract}

KEYWORDS: Women, Professionalization, Normalists, Bank Workers.

\section{INTRODUÇÃo}

Virginia Woolf, escritora e feminista inglesa que viveu na primeira metade do século XX, afirmou em uma palestra para a Associação Nacional de Auxílio às Mulheres, na Inglaterra, em 1931, que era difícil saber o que era uma mulher antes que ela pudesse expressar-se em todas as artes e profissões abertas às capacidades humanas. Woolf (2012), usando de sua fina ironia, concluíra que foi por causa do preço baixo do papel que as mulheres deram certo como escritoras antes de dar certo nas demais profissões.

Indo ao encontro às reflexões de Woolf, perguntaríamos: Por que as mulheres "deram certo" na profissão bancária somente a partir da década de 1960, em várias partes do mundo? Ou, como explicar a feminização da profissão de professora primária já nas primeiras décadas do século XX?

Segundo Rose-Marie Lagrave, no último volume da coleção História das Mulheres no Ocidente, o século XX escreveu a entrada maciça das mulheres na educação e no trabalho assalariado, mas o fez legitimando as desigualdades ao reinventar ou perpetuar a segregação por sexo na formação e no mundo do trabalho. Foi este paradoxo que sutilmente marcou o século, pois ao serem abertas as oportunidades de escolarização e trabalho às mulheres, estas foram remetidas a carreiras ou profissões consideradas adequadas ao seu sexo, limitadas pelo feminino (Lagrave, 1991).

No Brasil, o ingresso das mulheres das camadas médias no mercado de trabalho acontece entre as décadas de 1960 e 1980, não por acaso, período escolhido como recorte temporal da pesquisa aqui apresentada. 
Este artigo pretende discutir a profissionalização de mulheres de classe média no Brasil entre as décadas de 1960 e 1980. O que se denomina aqui por profissionalização vai além da escolarização e da formação profissional, mas sobretudo pelo desejo - dadas as condições históricas favoráveis - das mulheres em seguir uma carreira profissional. Utilizando a metodologia da História Oral e os aportes teóricos sobre memória e narrativa, o que veremos a seguir são histórias de mulheres como Nair, Vera, Fernanda, Marta e Leonora, que se formaram no Curso Normal, exerceram a profissão de professora, mas trocaram essa profissão pelo ingresso em bancos públicos. O que se busca é compreender através de suas trajetórias como as mudanças introduzidas no Brasil a partir da década de 1960, sejam as medidas de política econômica, de ingresso no Ensino Superior e na legislação afetaram a profissionalização das mulheres revelando mudanças ou permanências no tocante às tradicionais ocupações femininas.

$\mathrm{Na}$ primeira parte do artigo discute-se o contexto em que emergem as normalistas, como estas se consolidaram como uma típica profissão feminina desde as primeiras décadas do século XX, e como ainda nas décadas de 1960 e 1970 se apresentava, muitas vezes, como a única opção de formação e trabalho para as mulheres. Em seguida, passa-se à análise das mulheres na profissão bancária. Por último, abordam-se mais detalhadamente as carreiras desenvolvidas por estas cinco mulheres, os lugares que ocuparam ou os lugares que queriam reservados para elas.

\section{Algumas Questões teóRICAS E Metodológicas}

A pesquisa apresentada neste artigo é resultado de Dissertação de Mestrado em História (Geroleti, 2013) ${ }^{1}$, inserindo-se no campo de estudos da história das mulheres e da história de gênero.

O tema da pesquisa teve início com Trabalho de Conclusão de Curso de graduação em História, no qual entrevistei mulheres que haviam ingressado no Banco do Estado de Santa Catarina (BESC) entre as décadas de 1960 e 1980 na cidade de Florianópolis (Geroleti, 2010) ${ }^{2}$. Percebi, entre as bancárias entrevistadas, que as três que tiveram a trajetória de escolarização entre as décadas de 1960 e 1970 apresentavam uma formação comum, o curso normal. Com as fontes iniciais já selecionadas no trabalho de conclusão fui em busca de mulheres bancárias de um grande banco público federal ${ }^{3}$, aquele que mais admitiu mulheres entre as décadas de 1960 e 1980. Realizei entrevistas com quatro ex-funcionárias deste banco, sendo que duas delas haviam sido professoras formadas pelo Curso Normal.

Assim, cheguei ao conjunto das cinco entrevistas aqui agrupadas. Destaco que as cinco entrevistadas Nair, Vera, Fernanda, Marta e Leonora - serão identificadas por pseudônimos por opção delas próprias ao concederem as entrevistas ${ }^{4}$. Também efetuei pesquisa em materiais disponibilizados pelos dois bancos públicos, bem como em jornais e bibliotecas da cidade de Florianópolis. Tendo como fonte principal entrevistas orais, diante do debate ${ }^{5}$ sobre sua definição, se é uma metodologia, uma técnica ou umadisciplina, entendo a História Oral como uma metodologia de pesquisa, que consiste nautilização de entrevista semiestruturada, gravada e transcrita.

Trabalhar com história oral remete às sensíveis questões da memória e também da história. Emblemático da mudança da nova relação com o tempo, a partir da segunda metade do século XX, o conceito de memória foi sendo reformulado, afastando-se da hierarquia entre memória e história, como no tempo de Halbwachs, até desconsiderar a primeira como objeto da segunda, como afirmara Pierre Nora (1993). Para Enzo Travesso (2007), atualmente trata-se de perceber os jogos e os usos da memória no tempo presente, como eles constroem discursos, identidades e dependem das relações de força e poderes políticos. Neste sentido, o uso da história oral enriquece a pesquisa histórica.

Fui a campo tendo em mente os ensinamentos de Eclea Bosi (2003) de que a fonte oral sugere mais que afirma e de que a memória tem seus desvios, seus preconceitos, sua inautenticidade, e que era preciso interpretar tanto a lembrança quanto o esquecimento; também com os ensinamentos Para Alessandro 
Portelli (1997), para o qual as fontes orais são fontes narrativas. Assim, compreendo que as narrativas sobre as mulheres permitirão um entendimento de suas trajetórias e visões de mundo, ciente de que da memória sempre "fica o que significa" (Bosi, 2003). Concordando com Portelli (1997, p. 36), entendo que "o trabalho histórico que se utiliza das fontes orais é infindável, dada a natureza das fontes; o trabalho histórico que exclui fontes orais, quando válidas, é incompleto por definição".

É a análise de gênero que permeia a pesquisa, a qual dialoga com as historiadoras Joan Scott, Michelle Perrot e Luisa Passerine. Como assinalou Luisa Passerine (2011), gênero e história oral não são mais considerados assuntos de vanguarda. No entanto, para a autora, gênero ainda é uma categoria útil para a História Oral, caso sejam adotados uma série de cuidados que o entrelaçamento entre a história de gênero e a história oral exige. Seguindo recomendações de Passerine, o gênero deve estar aliado a outras categorias, como classe, raça e geração. Desta forma, as personagens do processo histórico em análise são mulheres de classe média, brancas e que viveram sua mocidade entre as décadas de 1960 e 1970. A definição de classe adotada na pesquisa está relacionada aos bens, padrão de consumo e os projetos de futuro, como o acesso ao ensino superior, aos quais tiveram acesso as classes médias urbanas após as reformas do governo brasileiro implantadas ao final da década de 1960 (Almeida e Weis, 1998).

Conforme Perrot (1989, p.15), um dos problemas encontrados na história das mulheres são as poucas fontes escritas deixadas por mulheres, pois "os modos de registro das mulheres estão ligados à sua condição, ao seu lugar na família e na sociedade”. Em artigo publicado em 1992, Scott diz que o campo da história das mulheres nasceu ligado à política. No entanto, a história das mulheres não deixa de existir quando também se faz uso da teoria de gênero, pois política e teoria estão imbricadas (Scott, 1992). Quero destacar que, embora busque enfatizar o gênero, no sentido da categoria de análise que Scott (1990) lhe deu, tenho ciência de que também estou fazendo história das mulheres.

\section{O CURSO NORMAL: UMA TÁTICA DE INDEPENDÊNCIA}

"Sim, eu fui normalista" ${ }^{6}$. É assim que Nair ${ }^{7}$, Vera $^{8}$, Fernanda $^{9}$, Marta $^{10}$ e Leonora ${ }^{11}$ se autodenominaram desde a primeira entrevista.

A Escola Normal, criação europeia, foi instalada inicialmente na cidade de São Paulo em meados do século XIX visando à formação de professores primários. Ainda na segunda metade do século XIX, e após a instauração da República no Brasil, mudanças importantes em relação à educação alterariam consideravelmente a classe, o sexo e também o salário dos professores primários.

Conforme Hahner (2011), na segunda metade do século XIX a educação passou a ser vista como elementochave de progresso e desenvolvimento. Nesse processo, as mulheres, percebidas como educadoras naturais, deveriam ser educadas, pois eram as responsáveis pela formação dos filhos e da família. Antes mesmo do final do século XIX, as mulheres já representavam a maioria das jovens formadas na Escola Normal e também nas seleções de professores. Um amplo debate entre educadores, intelectuais, liberais e positivistas discutia se a profissão de professora primária - considerada por eles uma função maternal e no início vista como uma alternativa de trabalho às jovens - deveria ser exclusivamente ocupada por mulheres. Segundo Hahner (2011), os homens passaram a se perceber como minoria na profissão, e como usufruíam de outras opções econômicas, abandoram-la. Por seu lado, as mulheres, mesmo as da elite e com instrução, tinham ainda poucas opções de sequer continuar os estudos em nível superior ${ }^{12}$.

No final da década de 1920, embora a feminização do magistério já estivesse consumada, o Curso Normal continuou sendo incentivado pelo Estado. A década de 1930 trouxe importantes transformações no campo educacional no Brasil. Entre essas mudanças, destaca-se a criação do Ministério da Educação e a criação da Universidade de São Paulo (USP), em 1934. Era a primeira vez que o ensino público começava a ser pensando como política de governo visando à popularização da educação básica, gerando investimentos crescentes em escolas e demanda por professores (Aranha, 1996; Besse, 1999). A demanda crescente e a maior valorização 
da escolarização presente nos centros urbanos aumentou a necessidade de professores também em escolas rurais e distantes dos centros urbanizados.

Nas décadas de 1960 e 1970, contexto que compreende nossas entrevistadas, mesmo com a expansão do Ensino Superior, o Curso Normal ainda representava a primeira opção de formação de muitas jovens. Ao longo das entrevistas, percebi que os motivos que as levaram a terem optado pelo Curso Normal dependeu de uma conjunção de fatores, tais como a cidade em que moravam - se no interior ou na capital - e a origem social, que as possibilitava estudar em escola pública ou particular, que viabilizaria seguir com os estudos após o ginásio, chegando à Universidade. Entretanto, todas concordaram com um motivo, como afirmou Leonora: "Uma jovem, seguindo o caminho normal, seria professora".

Nair, Vera e Fernanda nasceram e moraram na cidade de Florianópolis, capital do Estado de Santa Catarina. Nair e Vera viveram sua mocidade na década de 1960, Fernanda, no início da década de 1970.

Nair tinha 16 anos quando se formou no Curso Normal. Como ainda não podia dar aulas devido à pouca idade, conta que criou uma espécie de "escolinha" na casa em que morava, com a ajuda do pai.

Meu pai fez uma mesa, tinha um quadro negro e eu comecei a dar aula para a gurizada da rua toda, catei aluno, inventei na verdade, foi em 1960. Na verdade, naquela época não existia pré-escolar, porque eu peguei toda a gurizada aqui do Estreito, fui de casa em casa, peguei quem nunca tinha ido para escola ainda (Nair, entrevista citada).

Nair ressalta que se formou no Curso Normal por vocação, pois gostava de dar aulas, mas também por falta de opção, pois "quando me formei no Normal Regional, que era específico para dar aula principalmente no interior, em escola isolada, eu queria continuar estudando". Com a frase não terminada, mas compreendida no decorrer da entrevista, percebi que Nair não pretendia parar com os estudos após o Curso Normal, entretanto, como a escola mais próxima, localizada no continente ${ }^{13}$, oferecia apenas o Curso Normal, destinado a formar professores que se deslocariam para o interior, ela acabou nele se formando. Enquanto dava aulas "voluntárias" em casa, iniciou um curso técnico em Contabilidade por indicação do irmão, que era bancário. Em 1964 entrou para a Universidade Federal de Santa Catarina, recém-criada na cidade de Florianópolis, no curso de Filosofia.

Vera formou-se no Curso Normal do colégio Coração de Jesus, tradicional colégio feminino das elites do Estado de Santa Catarina, uma instituição privada dirigida por freiras de ascendência germânica e o primeiro colégio do Estado a oferecer o Curso Científico às jovens, nível de ensino que dava acesso à Universidade. Conforme pesquisa de Stella Maris Sartori Martini (2011), que analisou a trajetória de exalunas que cursaram o Científico entre 1949 e 1960, este colégio preparava as jovens das camadas altas da sociedade para o ensino superior, mas sem descuidar de transmitir-lhes uma educação católica e burguesa. Vera optou pelo Normal ao invés do Científico ou do Clássico ${ }^{14}$, segundo conta, por influência das mulheres de sua família, tias e primas, que também já eram professoras. Vera conta que "quando fazia o Magistério, no último ano já trabalhei como professora durante dois anos no colégio Coração de Jesus e aí no colégio começaram a exigir que eu fizesse pedagogia, aí eu saí". Deixou a profissão de professora e em seguida foi trabalhar em um programa do Ministério da Educação por período determinado. Casou-se nesse período e em seguida ingressou na Universidade Federal de Santa Catarina, formando-se no curso de Administração de Empresas. Apesar de não ter necessidade de trabalhar desde cedo, Vera diz que nunca pensou em se dedicar somente à família e ao marido, mas sim a ter uma profissão, incentivo que ela atribui aos exemplos das mulheres da família, a mãe, irmãs, tias e primas. Vera recordou-se ainda que, no período em que ingressou na Universidade, poucas colegas que também cursaram o Normal a acompanharam; passado algum tempo é que as colegas voltaram a estudar, fato que ela também atribui ao incentivo pessoal das mulheres da família, que também ingressaram na Universidade.

Já Fernanda, que sempre estudou em colégio público, conta que sempre gostou da área da educação, e o Magistério foi sua primeira opção. Oriunda de família simples, como ela se define, contou que apesar de exercer a profissão de bancária durante muito tempo por motivos financeiros, "eu sempre fui professora, 
juntei a bancária com a professora, dava aula à noite, sempre fiz os dois paralelos, tanto que na educação eu vou me aposentar daqui a sete anos". Como podemos observar pelo depoimento, Fernanda tinha certeza de que seguiria a profissão de professora, logo, para ela a escolha da formação no curso normal não indicou ter sido um acaso.

Para Nair e Fernanda, o Curso Normal representou a única oportunidade de formação no local em que moravam, para Vera, foi uma opção. A formação das três permite compreender a estratégia do Estado brasileiro, pois a formação no curso normal ia das mulheres da elite às jovens sem oportunidades. Se para as mulheres de classe alta e da elite formar-se no curso normal tratava-se de uma espécie de "dote" cultural, pois a maioria não chegava a exercer a profissão, a estratégia de escolarizar as mulheres para educar os jovens cidadãos da nação visava às jovens das classes médias e baixas que, sem oportunidade de casamento, teriam a oportunidade de serem professoras. Estariam, assim, servindo à nação, ao mesmo tempo em que não afrontariam os costumes exercendo profissóes consideradas inadequadas.

Para Marta e Leonora, a formação no curso normal seria a forma mais fácil para seguir uma profissão. Ambas nasceram e moraram até sua mocidade no interior do Estado de Santa Catarina, respectivamente nas cidades de Laguna e Rio do Sul. Leonora também estudou no colégio particular, católico e feminino de sua cidade, formando-se no Curso Normal. Marta também optou por fazer o Curso Normal, embora tivesse a opção de fazer o Científico em outro colégio da cidade. Ambas ressaltaram que pretendiam ter uma profissão, tornarem-se independentes. Leonora, logo que se formou, em 1968, começou a dar aulas no mesmo colégio em que havia estudado. Em 1970, prestou concurso para professor do Governo do Estado de Santa Catarina, foi aprovada e começou a dar aulas em escolas públicas da região. Leonora recordou que, na época, "para lecionar a gente tinha que começar no interior e tinha que viajar, andar a pé em estrada de barro, pegar dois ônibus; se quisesse lecionar para o Estado seria dessa forma”. Marta também comentou sobre as dificuldades para dar aulas nas escolas públicas, pois "como a escola ficava fora da cidade, demorava cerca de duas horas para chegar, andando pela estrada de barro até a escola”.

Segundo Marta, a experiência de professora foi interessante, mas seu objetivo mesmo era ir para a capital, Florianópolis, e ingressar na universidade. Leonora também não pretendia seguir a carreira de professora, mas optou pela profissão porque:

$\mathrm{Na}$ época, em Rio do Sul, não tinha opções de emprego para as mulheres. Era difícil, naquela época para as mulheres saírem para fazer faculdade; tinha que ser fora [da cidade]. Então, o que a gente pensava, lógico, queria ser independente, seguindo pelos caminhos normais, seria professora. A minha mãe tinha comércio e eu ajudava muito, mas eu queria ter uma profissão minha (Leonora, entrevista citada).

Pelos depoimentos de Marta e Leonora pude perceber que a opção pelo Curso Normal não ocorreu apenas por vocação ou por desejo de seguir a profissão de professora, mas sim como uma tática ${ }^{15}$ de independência porque era a única alternativa na cidade onde moravam que lhes daria uma profissão. O desejo de seguir uma profissão estava presente em ambas. Compreende-se que o Curso Normal era uma alternativa de profissionalização das duas jovens, principalmente porque moravam em cidades onde não havia chegado ainda o ensino superior, o que exigia a troca de cidade se quisessem frequentar um curso universitário.

Todas as cinco entrevistadas mostraram que desejavam ter uma profissão e viam no Curso Normal uma tática para tal. Se na década de 1960 o Curso Normal ainda era uma opção de formação buscada pelas jovens, entretanto, já não se apresentava mais como única alternativa, pois ingressar na universidade já fazia parte dos planos de Nair, formada em Filosofia; Vera, em Administração de Empresas; Fernanda, em Pedagogia; Marta, em Serviço Social, e Leonora, em Direito. Assim, se no início do século XX o Curso Normal era uma das únicas formaçóes vista como adequada socialmente às mulheres das elites e também das camadas médias, já na década de 1960, com a formação de uma nova classe média e de novas profissões trazidas pelo ensino superior na sociedade brasileira, as mulheres começavam a buscar novas profissões. Dentre as quais, os concursos públicos para os bancos, que estavam entre os mais disputados. 
No tópico seguinte, discute-se a troca da profissão de professora pela de bancária e como ela foi simbólica do ingresso das mulheres de classe média no mercado de trabalho brasileiro. Em seguida, discute-se como tal mudança foi reveladora, em realidade, de uma permanência no tocante às tradicionais ocupações femininas.

\section{O BANCO: UMA CARREIRA PROMISSORA}

Nair, Marta e Leonora largaram a profissão de professora e foram trabalhar em um banco na década de 1960. O mesmo acontece com Fernanda e Vera na década seguinte. Os motivos para o ingresso na profissão de bancária são variados,todavia, alguns são comuns: todas elas desejavam a disputada carreira no banco. Nair, Vera e Fernanda ingressaram no BESC; Marta e Leonora, em um grande banco público federal.

O ingresso no banco foi através de concurso público, caso de Marta e Leonora, ou por prova interna para Nair, Vera e Fernanda. Nair, aliás, não chegou a fazer prova interna, visto que o BESC ainda não havia sido inaugurado, conforme narrou:

O meu irmão era do Banco do Brasil de São Paulo, casado, e a mulher dele era irmã de um dos fundadores do Besc. Meu irmão, quando soube que estavam montando um banco, disse que eu estava fazendo contabilidade à noite. Eu dava aula para gurizada durante o dia e já fazia técnico em contabilidade à noite. Chamaram-me em dezembro de 1961 para fazer parte do grupo de organização do banco; mal tinha datilografia, fiz bem rápido o curso de datilografia, e fui. Eu tinha só 17 anos. (Nair, entrevistada citada)

Nair questionou-se e, ao mesmo tempo, expressou admiração pelo fato de os integrantes da comissão fundadora, que eram ex-funcionários do Banco do Brasil, não terem se recusado a trabalhar com mulheres, já que os concursos públicos do banco citado por Nair ainda não permitiam a inscrição de mulheres. Entretanto, a explicação encontrada por ela está no fato de que "trabalhávamos sábado, domingo e feriado na casa deles, porque o banco tinha que ser aberto, então, a gente não tinha hora, levava um monte de papel para a casa dele e nós íamos lá trabalhar”. Logo, para Nair, a explicação era a proximidade das funcionárias e a urgência do serviço a ser feito. A composição da comissão organizadora,bem como dos primeirosfuncionários e funcionárias do Besc estão na fotografia reproduzida abaixo:

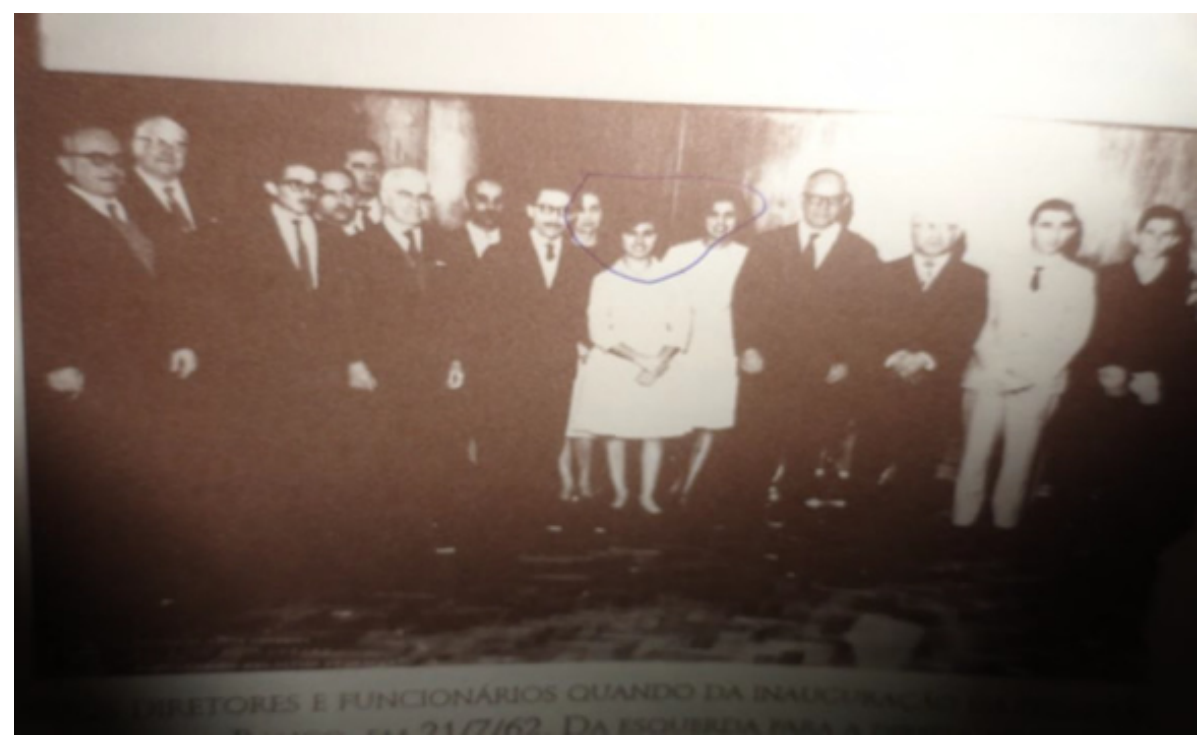

Figura 1: Foto oficial dos primeiros funcionários do BESC, 1962. Fonte: Fotografia reproduzida por Alvez Filho et al. (1997), p. 45.

Conforme Kossoy (2001), a fotografia é um meio de conhecimento do passado, não reconstitui os fatos passados nem representa a prova verdadeira. Nair está no centro da foto, entre as outras duas funcionárias emembros da comissão. Segundo Nair, e também o que se pode depreender pelo traje usado por elas, o banco 
criou uniforme para as funcionárias: um vestido clássico e discreto, pois, "na época, não tinha calça comprida; mulher não usava calça comprida, custou muito a poder usar calça comprida”.

Além da obrigatoriedade de usar saias ou vestidos, Nair disse que, no início, "fazia de tudo, passava no mimeógrafo, até que foram se formando os departamentos, separando os serviços; oitenta por cento da minha vida no banco fiquei no departamento de Crédito Rural". Entretanto, ressalta que, apesar de ficar no departamento de Crédito Rural, "acabei me dedicando ao treinamento de pessoal dentro do banco, usando os cursos que eu tinha fora do banco para fazer treinamento do pessoal; ia às agências, treinava o pessoal”. Depois de alguns anos, Nair passou a chefiar o departamento de Crédito Rural, passando por vários cargos dentro do banco.

Vera conta que passou por um processo seletivo para admissão no BESC, através de entrevista e prova. Quanto à mudança de profissão, diz que "não foi por acaso, eu trabalhava num programa na área da educação e tive interesse em trabalhar no banco, tinha um salário melhor". Já Fernanda conta que "seu sonho era trabalhar no banco", porque "naquela época, o banco abria portas. Era importante trabalhar no banco, dava status e tinha muito bom salário". Para esta, a oportunidade do trabalho no banco surgiu quando seu antigo patrão, para o qual Fernanda fazia os pagamentos no banco, questionou-a:

Ele perguntou para mim se eu não tinha vontade de trabalhar no BESC. Eu disse eu tenho, mas disse para ele que iria só se eu fosse ganhar mais. Ele disse eu acho que tu ias ganhar porque vai ser perto da agência central do banco que vai inaugurar e eles estão fazendo uma pré-seleção de moças para trabalhar na abertura de conta, setor que ficava bem na frente. Eu ainda lembro da foto (Fernanda, entrevista citada).

A foto referida por Fernanda está reproduzida abaixo.

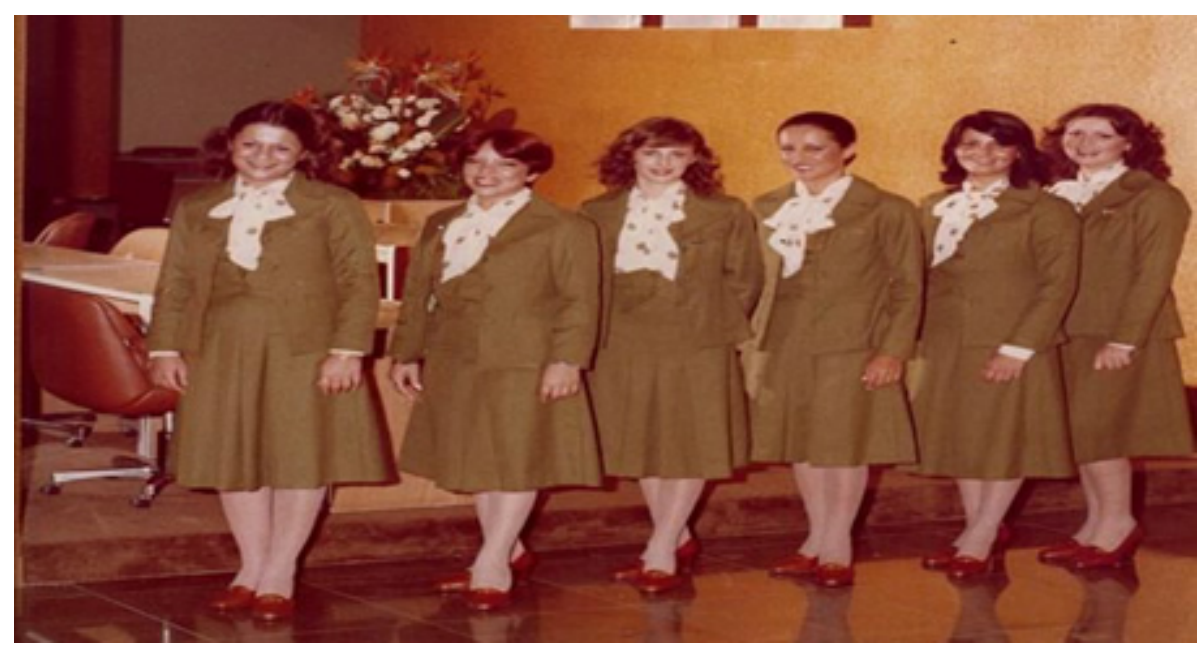

Figura 2: Recepcionistas na inauguração da Agência Central BESC, 1978.

Fonte: Álbum de inauguração de agências, disponível no acervo do Museu BESC.

Para fazer parte do grupo de recepcionistas do banco, Fernanda, a segunda da direita para a esquerda, participou do Projeto Moça Besc. Segundo consta no jornal informativo do BESC, Informativo Mural (1987, p.15), o projeto inicialmente "manteve contato com os colégios objetivando seleção de estudantes, a nível de segundo grau e superior, para suprir as diversas vagas existentes nas agências através de entrevistas individuais; os critérios estabelecidos foram boa aparência e desembaraço" ${ }^{16}$.

Como pode ser observado, os pré-requisitos exigidos das candidatas traziam representações de gênero com um reforço da feminilidade ao valorizar a boa aparência, qualidades consideradas intrinsecamente femininas. Fernanda passou no teste e "fui ser garota besquiana, como a gente era chamada". Sobre a seleção, Fernanda ressalta que, "na época, era um teste, não era um concurso, mas como eu já tinha datilografia, que eu tinha feito na época, era uma entrevista que era feita no setor de recursos humanos”. 
Já Marta e Leonora ingressaram no banco público federal via concurso público, respectivamente nos anos de 1969 e 1971. Neste banco, até 1968 as mulheres eram impedidas de participar de seus concursos. Tal proibição foi abolida com a publicação da Lei 5473, de 1968, que proibiu a discriminação de sexo em cargos sujeitos à seleção nas empresas públicas e privadas no Brasil ${ }^{17}$. Marta participou do primeiro concurso que permitiu a inscrição de mulheres, em 1969, influenciada pelo irmão de uma amiga, que já era funcionário do banco na cidade de Laguna. Leonora prestou o concurso que ocorreu dois anos depois, em 1971, também por influência de uma amiga, que havia passado no primeiro concurso em sua cidade, Rio do Sul.

Depois de admitidas nas agências do banco em suas respectivas cidades, Marta e Leonora pediram transferência para a capital Florianópolis. Para Marta, o motivo da mudança era o ingresso na universidade, embora os cursos que pretendia fazer - Jornalismo ou Psicologia - ainda não tivessem sido criados na Universidade Federal de Santa Catarina e a única opção seria mudar-se para outro estado: Curitiba ou Porto Alegre. Entretanto, conta que devido à doença de sua mãe desistiu da ideia e, por exclusão, quando conseguiu a transferência em 1975, ingressou no curso de Serviço Social. Já Leonora, o motivo da mudança para Florianópolis foi o casamento, em 1978. Como a cidade só possuía uma agência, as duas acabariam trabalhando juntas. Leonora, que já exercia a função de caixa desde 1975, passou a exercer a mesma função na nova agência. Marta foi trabalhar no setor de telecomunicação. Sobre a troca de profissão, Marta assim expressou seus motivos:

A pessoa tem outras vocações, mas elas vão trabalhar num banco porque era um emprego muito bem conceituado na época. Quando chegava um funcionário novo na minha cidade, todas as moças queriam casar com aqueles rapazes, porque eles ganhavam bem, tinham uma carreira garantida. Não era qualquer um que conseguia entrar no banco; as pessoas eram tidas como pessoas de boa capacidade porque eram exigidas muitas coisas na época (Marta, entrevista citada).

Durante a entrevista, questionada se pensava em voltar a dar aulas, Leonora afirmou que:

Não pensei em voltar a dar aula porque para lecionar a gente tinha que começar no interior e tinha que viajar, andar a pé, andar em estrada de barro, pegar dois ônibus. Se quisesse lecionar para o Estado seria dessa forma. No banco eu não precisava viajar, ficava no centro, perto de casa. E também tinha uma carreira, era muito mais interessante que professor do Estado, um emprego que dava mais estabilidade, mais futuro (Leonora, entrevista citada).

Leonora, embora não soubesse precisar em valores o salário de ingresso no banco público, afirmou que passou a ganhar muito mais do que ganhava como professora. Conforme mostrou a pesquisa de Auras (1997), no ano de 1969 mais da metade dos professores do Curso Normal recebiam menos de CR \$ 100,00 mensais, numa escala que ia de menos de CR $\$ 100,00$ a mais de CR $\$ 600,00$. Aliado à baixa remuneração, segundo Auras (1997), havia o problema da instabilidade funcional, sendo que o tempo de permanência do professor do Estado no Curso Normal era de no máximo cinco anos. Fato que corrobora as afirmações de Marta e Leonora, citadas acima, de que tinham que se deslocar para escolas distantes umas das outras e até de municípios diferentes, deixando o professor sem tempo para melhor preparar suas aulas (Auras, 1997). Assim, pelos depoimentos de Marta e Leonora, podemos perceber que a opção pelo trabalho no banco se deu de forma consciente, trocando a carreira "sofrida" de professora pela "promissora" carreira no banco, um emprego que daria "mais futuro".

Um motivo comum destacado pelas cinco entrevistadas para a mudança de profissão foi o salário. Nair entrou no BESC ganhando salário mensal de Cr\$ 17 mil cruzeiros (Alves Filho et al, 1997). Fernanda passou a ganhar o dobro quando entrou no banco. Vera referiu-se ao bom salário do banco.

Os anúncios de salários para algumas profissões na década de 1960 e 1970 eram, em geral, inferiores a esse valor. Para um programador de computadores, oferecia-se CR \$ 15.000,00, "ganhos acima da média", segundo o anunciante (O Estado, 1979). Nessa mesma edição do jornal, a Associação dos Trabalhadores em Transportes Rodoviários de Itajaí reivindicava o aumento do salário dos motoristas para CR \$ 8.000,00 ( $O$ Estado, 1979). Na seção de classificados havia tantos anúncios da Escola de Datilografia de Florianópolis 
quanto de ofertas de emprego para secretárias-datilógrafas, cujo curso de datilografia era pré-requisito para a função, mas não havia indicação de salário (O Estado, 1979).

Esse "bom salário" a que se referiram devia-se a uma conjunção de fatores. Em Florianópolis, nas décadas de 1950 e 1960, o poder aquisitivo dos habitantes em geral era muito baixo. Encontramos indícios sobre o "drama" dos funcionários públicos em matérias dos jornais no final da década de 1950. Em uma delas, intitulada pelo colunista Osvaldo Melo como "Grito d'alma”, um leitor escreve ao jornal informando sua situação precária:

Sou um pequeno funcionário público. Sou casado, tenho mulher e três filhos. Tenho de sustentar toda a família, ir ao mercado todo dia, comprar pão caro e miúdo. Moro numa casa de madeira, pequena e velha. Pago 500 cruzeiros de aluguel. Meu ordenado é miserável, então, quando alguém adoece é um verdadeiro inferno. Sei, Sr. Osvaldo, que não tenho o direito de me queixar ao senhor. Já disse “o pobre não pode mais viver” ( O Estado, 1958, p. 3).

Segundo Mello e Novais (1998), a industrialização e a urbanização crescentes da sociedade brasileira entre as décadas de 1950 e 1970 fizeram com que o funcionário público das carreiras médias tivesse seu salário achatado. Com a "modernização" da sociedade ou o "capitalismo tardio" a partir da década de 1950, cresceu a demanda por profissões especializadas para atender as empresas públicas e privadas, bem como a alta administração do Estado. Dessa forma, ocupações que não exigiam qualificação ou formação no ensino superior passaram por defasagens salariais (Mello e Novais, 1998).

A percepção de futuro na carreira bancária certamente passava pelas qualidades que Leonora descrevera, como "ganhar bem, ter uma carreira, ter estabilidade, além de não precisar viajar para o interior, nem trabalhar aos sábados". Entretanto, essa "percepção de futuro" estava atrelada à posição ocupada pelo referido banco público federal dentro da burocracia do Estado brasileiro à época. A história desse banco público foi escrita em meados da década de 1950 por Afonso Arinos de Mello Franco e Cláudio Pacheco, com viés de história econômica, pois, segundo os autores, a história do banco se confundia com a própria história econômica do Brasil (Franco e Pacheco, 1979). Primeiro banco criado no Brasil desde o Império e passando por várias fases: até meados da década de 1960 fazia o papel de Banco Central do Brasil, ou seja, controlava a emissão de moeda e fiscalizava os demais bancos do mercado financeiro, até a criação do Banco Central, em 1964. Na expressão de Mello e Novais (1998, p. 594), este banco era o "poderoso do sistema financeiro", posição de prestígio na burocracia do Estado brasileiro até meados da década de 1980, além de ser uma carreira muito disputada nos concursos públicos.

Conforme frisou Marta, "um funcionário do banco era muito bem conceituado dentro da sociedade, porque não era qualquer um que conseguia entrar". Marta confirmara que era "um emprego muito bem conceituado na sociedade da época e exercido por pessoas de boa capacidade". Aqui é importante considerar que a afirmação de Marta de que não era "qualquer um que conseguia entrar" revela uma clara questão de classe; de classe média precisamente. Já na década de 1960 e após a publicação da Lei 5473/1968, quando os concursos públicos passaram a aceitar candidatos de ambos os sexos, foram as camadas médias, os homens, mas principalmente as mulheres, que primeiro tiveram acesso a eles. Aliás, é o concurso público o símbolo do surgimento da classe média a partir da década de 1960 no Brasil. Conforme Mello e Novais (1998), a exigência de qualificação fundada na educação superior começava com o concurso público, que cada vez mais passava a ser exigido pelos governos. Nesse período, já era a "máquina capitalista" que definia tanto a classe quanto a hierarquia do trabalho na sociedade brasileira. Segundo os autores, a sociedade urbanizada olhada em seu conjunto permitia perceber que:

Há a família do trabalhador comum, do migrante rural recém-chegado e a dos citadinos pobres, de todos os que se encontram na base do mercado de trabalho. Há a família do trabalhador especializado. Há a família de classe média, baixa ou alta. Há a família dos empresários, pequenos ou médios. Há a família dos magnatas. Pela casa podemos reconhecer de que classe social faz parte da família. Tem empregada doméstica? Quantas? Tem cozinheira, arrumadeira, lavadeira, passadeira, babá ou só uma para todo o serviço? (...) Olhemos o que há para comer. O jantar é servido à francesa ou por mordomo? Tem automóvel ou não? (Mello e Novais, 1998, p. 600). 
Importante destacar o contexto político e as reformas promovidas pelo governo que assume após golpe civil-militar de 1964. A aliança entre classe média e o Estado foi fortalecida no período da ditadura militar no Brasil, principalmente entre os anos do chamado "milagre econômico", entre fins dos anos 1960 e início dos anos 1970. Conforme os economistas Prado e Earp (2009), entre 1967 e 1973 a política econômica imposta pelo então governo e as várias reformas promovidas no campo fiscal, creditício e trabalhista, desde o novo governo instaurado em 1964, ocasionaram a concentração de renda no Brasil. No setor financeiro destacase a reforma bancária que deu início ao processo de mecanização dos serviços administrativos e bancários, e a introdução dos computadores foi um caminho sem volta assumido pelos bancos.

A partir da década de 1970 adistribuição de renda piorou devido a uma conjunção de fatores, como as reformas citadas anteriormente, que combinaram ganhos muito pequenos nos grupos de renda próxima ao salário mínimo e ganhos extremamente elevados nos grupos de alta renda.Entre os fatores geradores da desigualdade de renda, destaca-se a educação, ou seja, o nível de escolaridade ocupou um destaque especial, já que com o estrondoso crescimento econômico entre os anos do "milagre" a demanda por mão de obra qualificada e escolarizada crescia acima das demais. Assim, os tecnocratas do governo beneficiaram as classes alta e média da sociedade, que tinham acesso à educação superior. Melhoraram seu nível de vida, bem comolhes concederam cargos públicos criados com a modernização econômica do Estado (Earp e Prado, 2009).

Se fôssemos classificar as cinco entrevistadas, diríamos que todas elas estariam na posição de classe média. Como já ressaltado nas questões teóricas e metodológicas, esta classificação não se faz aqui pela via estritamente econômica, pois são os projetos de futuro pretendidos e acessados por elas que demonstram "sonhos de classe média", como o concurso do banco e o acesso ao ensino superior. Conforme Mello e Novais (1998), todas as ocupações em empresas públicas que passaram a exigir concurso eram consideradas como uma excelente profissão.

A profissão de bancário, que agora passava a ser de bancária também, era uma profissão de prestígio, sobretudo nos bancos públicos. Em Santa Catarina, conseguir um emprego no BESC era também sinônimo de carreira promissora, pois representava o banco oficial do Estado, ligado às elites políticas catarinenses. No caso de Marta e Leonora, significava ter conquistado uma carreira de prestígio e muito promissora. Já na década seguinte, 1980, o futuro da profissão bancária passou por grandes mudanças após o ingresso das mulheres nos bancos, assunto que será tratado no próximo tópico.

\section{GÊNERO E CARREIRA NO BANCO}

A literatura sobre gênero e carreiras profissionais no Brasil é muito rica e não poderá ser esgotada aqui ${ }^{18}$.

Em se tratando de carreiras administrativas, a pesquisa de Queirolo (2014) mostrou que em Buenos Aires entre as décadas de 1910 e 1950 cresceu significativamente a participação das mulheres nas carreiras administrativas, no entanto, tal crescimento concorreu para a construção da desigualdade.

Sobre as careiras nos bancos existem poucos trabalhos historiográficos. A maioria das publicações da sociologia mostrou a categoria bancária sob o viés da ação política enquanto movimento de trabalhadores ${ }^{19}$ . Identifiquei apenas uma tese feita no âmbito da História, de Aurea Tomates Petersen (1999), que tratou sobre o ingresso das mulheres nos bancos do Estado do Rio Grande do Sul desde a década de 1920. Petersen mostra como desde a década de 1920 as funções auxiliares, como recepcionista, ascensorista ou secretária, foram preenchidas por mulheres, sendo que os primeiros concursos que admitiam mulheres ocorrem ao final da década de 1960.

Uma referência sociológica das mulheres nos bancos vem da pesquisa da socióloga Liliana Segnini (1998) desenvolvida sob a forma de livre docência. A autora teve como estudo de caso o extinto Banco do Estado de São Paulo (BANESPA), com o objetivo de compreender o trabalho e as carreiras das mulheres nos bancos. A autora observou, com base em relatórios da Organização das Nações Unidas (ONU) e da Organização 
Internacional do Trabalho (OIT), que em 1990 era o setor de serviços da economia que verificava os mais altos índices de participação das mulheres no mundo. Também no Brasil, em 1989, segundo dados do Instituto Brasileiro de Geografia e Estatística (IBGE), era o setor de serviços que mais empregava mulheres, setor no qual se inserem os bancos (Segnini, 1998).

Em 1969, quando foram permitidas as primeiras inscrições de mulheres no concurso do banco público federal em análise, o trabalho neste banco ainda era visto como um "ambiente só de homens", motivo da preocupação do pai de Leonora quando ela passou no concurso. Segundo conta, "o pai ficou bastante preocupado porque era um ambiente só de homens, só que tinha muitos amigos dele, pessoas conhecidas que diziam ‘seu João, é um ambiente muito bom’. Aí ele deixou”. Já na década de 1980, quando uma jovem prestasse o concurso para o banco, dificilmente seu pai ainda o consideraria um ambiente masculino.

A exemplo das cinco entrevistadas, muitas outras mulheres foram admitidas nos dois bancos públicos entre as décadas de 1960 e 1980. Só no banco público federal em que Leonora e Marta trabalhavam foram admitidas mais de 51 mil mulheres entre 1969 e $1990^{20}$. Já no BESC, banco de Nair, Vera e Fernanda, embora não disponhamos de estatística oficial sobre o número exato de homens e mulheres no período. Fontes consultadas em pesquisa de Trabalho de Conclusão de Curso de graduação permitiram concluir que, na década de 1980, as mulheres representavam cerca de cinquenta por cento dos funcionários (Geroleti, 2010).

Pesquisa realizada na Argentina, também na década de 1980, intitulada El empleo de cuello rosa en la Argentina: El caso de un banco estatal mostrou como as mulheres representavam a maioria dos funcionários em um banco daquele país, apelidado de "emprego de colarinho rosa" (Fanelli, Gogni e Jelin, 1989).

Se Marta e Leonora ingressaram no banco a partir de 1969 num ambiente "só de homens", com Nair, Vera e Fernanda o ambiente não era visto muito diferente, dado que o BESC era considerado o "banco dos homens públicos".

O historiador Sérgio Schmitz, ao falar sobre a criação do BDE - Banco de Desenvolvimento de Santa Catarina, refere-se a este como uma iniciativa dos homens públicos (Schmitz, 1991). Da parte da elite catarinense, dispor de um banco oficial também era um dos seus objetivos, pois todos os Estados mais prósperos e desenvolvidos da Federação tinham o seu. Nascia, então, o BDE, que em 1969 passou a se chamar BESC - Banco do Estado de Santa Catarina -, como resultado de uma decisão política, fato que o atrelou à cena política partidária catarinense durante toda sua existência. Segundo Schmitz (1991, p. 365), "o banco se confundia com o governo, seu maior acionista". Nesse sentido, interessa a compreensão de que os "homens públicos" que criaram o BDE representavam não apenas o sistema político em vigor em Santa Catarina, mas, representavam, sobretudo, também homens. Ainda segundo Schmitz (1991, p. 365), “o banco se preocupava com a formação de pessoal técnico de nível superior e médio, não só para o atendimento de seus quadros administrativos, como para o preenchimento das vagas do próprio Estado”.

Considerando a autoridade do Estado sobre a vida das pessoas, especialmente sobre a vida das mulheres, e como homens representavam a suprema maioria dos funcionários de banco e dos cargos políticos no período, qual era, então, o lugar das mulheres no banco? Pode-se supor que as indicações políticas para admissão e também o acesso a cargos comissionados dentro do banco tinham alvo certeiro: os homens.

As questões suscitadas pelos depoimentos de Nair, Vera e Fernanda mostram o lugar de homens e mulheres no BESC, demonstrando como homens e mulheres constituem experiências distintas. No tocante às relações de gênero no BESC, duas posições se sobressaíram: de um lado as relações eram vistas como uma "guerra de foice", do outro, como "maravilhosas". O que explicaria tal extremo?

Para Fernanda, as relaçóes com os colegas homens eram respeitosas. Nas suas palavras, os colegas eram "muito educados" e "tinham muita paciência com a gente". Importante considerar que Fernanda não disputou cargos comissionados no banco, ou seja, não disputou poder por cargos com os homens. Entretanto, isso não significa que a considero passiva ou que foi ela própria que não quis ascensão profissional. Entendo que se trata muito mais de condicionantes culturais e sociais, embora também de opções individuais. 
Vera disse que nunca se preocupou se estava trabalhando com homem ou mulher, diz que "sempre me considerei igual". Porém, quando perguntada sobre possíveis diferenças na forma de tratamento de homens e mulheres no trabalho, Vera ressaltou que tinha em relação à chefia, "eu tive chefes, assim, que o homem era prioridade". Contou que percebia certa diferença das mulheres em relação aos homens no acesso aos cargos de chefia. Em certa passagem, ressaltou um episódio em que ela achou que fora preterida porque era mulher. Segundo Vera, "na primeira promoção, todos entraram, menos eu. Aí na segunda vez que teve, apesar de que eu era mais nova, a segunda vez, então, eu entrei para técnico nível superior”.

Já Nair foi a que mais percebeu como conflituosas as relações entre homens e mulheres no BESC. Ocupou vários cargos comissionados durante a carreira, porém, segundo ela, era muito difícil de consegui-los. Nair diz que "fiz uma briga de foice". Segundo Nair:

Os homens não davam espaço, não! Tinha que lutar, tinha que fazer tudo certinho e mais alguma coisa para eles acharem que tu fizeste o mínimo. Eu era tinhosa, eu não me dava por vencida, sempre lutei. Eu sempre lutei pelo meu espaço, eu galguei todos os cargos dento do banco; só não fui diretora, mas fui diretora da Fusesc, nossa fundação, e foi por eleição (Nair, entrevista citada).

Nair foi a primeira mulher a ocupar o cargo de chefe de departamento no BESC, cargo imediatamente abaixo ao de diretor. A "briga de foice" de que fala Nair refere-se à sua trajetória dentro do banco, na qual, segundo ela, "era muito raro uma mulher em cargo comissionado", pois "eles achavam que os homens mereciam o cargo porque era pai de família, tinha que ganhar mais, isso eu cansei de ouvir".

Ainda sobre a relação com os colegas homens, Nair diz que "se dava bem no meio dos homens" e que "não fosse alguns que eram muito amigos, não tinha conseguido as coisas, porque a maioria gostava de mulher para a recepção, atender telefone, servir cafezinho".

Conforme ressalta Michelle Perrot (1988), é sempre o poder que move as relações entre homens e mulheres. Nair, ao mesmo tempo em que demonstra como conseguiu cargos na carreira do BESC, como aliarse aos homens, mostra o lugar na base da hierarquia do banco que era reservado às mulheres. Talvez por ter disputado o poder com os homens e lutar para ir além das ocupações consideradas adequadas às mulheres, Nair percebia relações de poder nas relações de gênero. Já Fernanda, por não ter brigado por espaço além de tais ocupações femininas, via estas como uma valorização das qualidades femininas, como explicou:

A mulher era valorizada porque não era vista só como ornamento do banco, tanto que nós éramos a linha de frente do banco: sempre tinha mulheres na recepção, entendeu. Abertura de conta: mulheres; secretária: mulheres; recepcionista e ascensorista: mulheres. A genteera valorizada para o lado bonito: do bem servir, do bem atendido, sabe, de capricho, que o homem não tem (Fernanda, entrevista citada).

O depoimento de Fernanda suscita inúmeras questões de gênero. $\mathrm{O}$ período a que se refere é, provavelmente, entre meados da década de 1970 - período em que entrou no banco e em que este chegou a ter 9.000 funcionários $^{21}$ - e durante a década de 1980. Essa "valorização da mulher" dita por Fernanda poderia representar a maior contratação de mulheres pelo banco, sobretudo na década de 1970 e início de 1980, período em que várias agências foram inauguradas por todo o Estado de Santa Catarina (MURAL, 1987). Neste período funções tradicionalmente consideradas como "femininas", como secretárias, recepcionistas, telefonistas e ascensoristas, expandem-se e eram ocupadas somente por mulheres. As funções de secretária e recepcionista eram funções gratificadas, ou seja, possuíam salários maiores que todas as demais funções não comissionadas no banco. Comissionadas ou não, a questão é por que as mulheres, embora tivessem ingressado por prova interna, ocupavam apenas um gueto de ocupações femininas.

A concentração em ocupações femininas e a valorização das mulheres apenas nestas funções, certamente, não era uma prática isolada no BESC. Quando Marta e Leonora ingressaram no banco público federal, a desigualdade de gênero ia da falta de banheiros femininos, da dificuldade de não poderem usar calças até a forma discriminatória como foram tratadas (Geroleti, 2013). 
A carreira de Marta iniciou no setor de atendimento ao público e foi até a função de caixa, exercida do final da década de 1980 em diante. Trabalhou em diversos setores, sendo que na maior parte de sua carreira manteve a jornada de seis horas. Marta não se referiu explicitamente à incompatibilidade entre cuidar dos filhos e trabalhar no banco, mas argumentou que o trabalho no banco era muito "burocrático e cansativo". Indagada se pensava em assumir posições hierárquicas no banco, Marta foi enfática:

Eu nunca pensei sinceramente, tenho amigas que pensaram e chegaram lá. Eu acho que toda mulher pode exercer cargo de gerente de banco, basta ela se sentir vocacionada, eu nunca senti vocação, inclusive, eu queria sair do banco e exercer uma profissão, mas eu fiz serviço social, eu fui ficando, aí daqui a pouco você passa a ganhar promoções automáticas, vai ficando (Marta, entrevista citada).

O Plano de Carreira e Salários (PCS) vigente quando Marta e Leonora entraram no banco valorizava o tempo de serviço prestado e a experiência acumulada; as promoções aconteciam por faixas, chamadas de letras, que iam aumentando em função do tempo de serviço, automaticamente (O Espelho, 1989). Segundo Marta, "a gente começava como auxiliar de escrita, depois escriturário, e de tempo em tempo era promovido por tempo de serviço automático".

Já a carreira de Leonora foi impulsionada desde seu início, como narrou:

Em princípio, assumi na carteira agrícola de Rio do Sul, maior do país em número de contratos. Primeira mulher na carteira. Em seguida, fui convidada a fazer uma substituição do chefe de serviço. Nesse meio tempo fiz um concurso interno para ser caixa, isso em 1973. Fiquei vinte e três dias em Londrina para depois assumir a função de caixa (Leonora, entrevista citada).

O fato de sua carreira ter sido impulsionada desde o início talvez explique a forma como Leonora via a desigualdade entre homens e mulheres no banco. Para ela, a maior dificuldade era o fato de as mulheres não poderem usar calça comprida: "no banco sempre fomos salário igual; a única coisa que nós tivemos uma dificuldade é que nós não podíamos usar calça comprida” ${ }^{22}$.

Marta e Leonora, assim como Nair, Vera e Fernanda, podem ser consideradas mulheres modernas ${ }^{23}$, que desejavam ter uma profissão, casaram-se e passaram a conciliar o emprego no banco com o nascimento dos filhos. Em certo momento, assumiram ter feito a opção pela família, reduzindo a carga horária depois do nascimento dos filhos ou saindo da função que exerciam.

O trabalho no banco, antes "ambiente só de homens" - como percebia o pai de Leonora -, mas também visto como uma profissão de prestígio foi se modificando ao mesmo tempo em que as mulheres passaram a tornar-se maioria nos bancos.

A ideia de que o ingresso das mulheres nos bancos ocorreu por que as mulheres teriam qualquer propensão natural ao trabalho bancário é em si mesma uma questão generificada. Antes de tudo, observa-se que foi a expansão do sistema capitalista, principalmente com o taylorismo e a racionalização do trabalho a partir da década de 1920, que possibilitou a emergência de profissões que poderiam ser preenchidas pelas mulheres no espaço urbano, no setor de serviços. Para Segnini (1998) há uma relação direta entre a qualificação e a feminização da profissão bancária. Segundo a autora, as qualificações que passaram a ser exigidas dos trabalhadores bancários, ocasionadas pela gradual introdução de máquinas de autoatendimento, foram o fator determinante, não só para a duplicação do número de bancários no Brasil, mas, sobretudo, para o número de bancárias.

A qualificação está ligada ao domínio do ofício; isto é, à combinação de conhecimentos materiais e de processos com as habilidades manuais exigidas por determinado ramo de produção. No trabalho bancário, o ofício era uma combinação de conhecimento contábil com o domínio de rotinas e serviços. Com a substituição dos serviços e registros manuais pelo trabalho das máquinas na década de 1980, o métier da profissão foi desaparecendo, período que coincide com a entrada maciça de mulheres no setor bancário.

Para Segnini (1998), o ofício de bancário foi um saber e um privilégio masculino, pois no período em que a profissão era considerada prestigiosa e valorizada socialmente, na década de 1960,somente homens com raras exceções - a exerceram. Por isso, conclui a autora que a análise do trabalho bancário deve levar 
em conta a qualificação requerida, pois as mulheres só se inserem de maneira expressiva nos bancos quando estes passam a requerer uma qualificação tradicionalmente vista como feminina: o trabalho repetitivo ligado à digitação de dados. Assim, as mulheres ao ingressarem nos bancos não substituíram o trabalho dos homens, mas sim ocuparam as vagas abertas pelo processo de automatização dos serviços bancários. Uma forma sutil de segregação da profissão.

\section{Considerações Finais}

O mercado de trabalho é um dos pilares da desigualdade de gênero, logo, discuti-lo e analisá-lo é uma forma de promover mudanças.

No Brasil, o direito ao salário igual entre homens e mulheres tenha sido adquirido ainda na década de 1930, no entanto, permanece nos dias atuais uma clara desigualdade de gênero nas mais variadas profissões. Dentre estas,a mais feminizada historicamente é a profissão de professora primária, percebida como um prolongamento das tarefas maternais, que apela para as virtudes da feminilidade e que ignorou os prejuízos salariais sofridos ao longo do tempo. Também sofrem o mesmo tratamento as profissóes de empregada doméstica, de profissional do setor da limpeza, do setor de vestuário, da costura e confecção, da saúde, e de enfermeira e auxiliar. A lista é longa e todas elas trazem consigo uma série de estereótipos associados ao feminino, à desvalorização profissional e salarial.

O processo de profissionalização das mulheres que ocorre no Brasil a partir da segunda metade do século XX caracteriza-se pela entrada massiva das mulheres de classe média no mercado de trabalho entre as décadas de 1960 e 1980. Neste período, muitas mulheres com formação de normalistas, profissão tradicional para as jovens até então, prestaram concursos e ingressaram nos bancos públicos. Por que essas mulheres escolheram ir trabalhar em um banco público ou por que os bancos passam a admitir mulheres no final da década de 1960 eram algumas das perguntas que se tentaram responder ao longo da pesquisa.

Destacaram-se aquiduas profissóes,a normalista e a bancária, mais precisamente a passagem de uma profissão à outra com o objetivo de analisar um processo histórico de profissionalização de cinco mulheres. Embora a carreira no banco prometia muito mais futuro, a análise da profissão bancária mostrou que tal mudança foi reveladora, em realidade, de uma permanência no tocante às tradicionais ocupaçóes femininas.

\section{BibLiOgRAFIA}

Abreu, A. R., P., Hirata, H., e Lombardi, M. R. (2016). Gênero e trabalho no Brasil e França - perspectivas interseccionais. São Paulo: Boitempo.

Alves Filho, A. et al (1997). Besc: uma idéia 35 anos depois. Florianópolis: Besc.

Aranha, M. L. A. (1996). A história da educação. 2 ed. São Paulo: Moderna.

Auras, G. M. T. (1997). Modernização econômica e formação do professor em Santa Catarina. Florianópolis: Ed. Da UFSC.

Banco do Brasil. (2012). Mulheres admitidas 1969 a 1990.[mensagem pessoal] Mensagem recebida por em 26 ag. 2012.

Besse, S. K. (1999). Modernizando a desigualdade: Reestruturação da ideologia de gênero no Brasil, 1914-1940. São Paulo: EDUSP.

Bosi, E. (2003). O tempo vivo da memória: Ensaios de Psicologia social. São Paulo: Ateliê Editorial.

Brasil. (1968). Lei no 5.473, de 10 de julho de 1968. Recuperado de: http://www.planalto.gov.br/ccivil03/leis/L5473.

Caminha, A. (1982). A Normalista. São Paulo: Ática.

Canedo, L. B. (1986). Bancários:movimento sindical e participação politica. Campinas (SP): Ed Unicamp.

Certeau, M. (2008) A invenção do cotidiano:1. Artes de fazer. Petrópolis:Vozes. 
Cunha, M. T. S. (2002). Diários Íntimos Memórias de Professores Normalistas. Em M.C.S. Campos e Silva (Org.), Feminização do Magistério: Vestígios do passado que marcam o presente (pp. 123-140). Bragança Paulista: Editora da Cidade de São Francisco.

Dallabrida, N., e Carminatti, C. J. (2007). O tempo dos ginásios: ensino Secundário em Santa Catarina (final do século $X I X$-meados do século XX). Campinas (SP): Mercado das Letras, Florianópolis: UDESC.

Earp, F. S., e Prado, Luiz C. D. (2009).O "milagre" brasileiro: crescimento acelerado, integração internacional e concentração de renda. En J. L. Ferreira e N. Delgado (Orgs.), O Brasil republicano: o tempo da ditadura - regime militar e movimentos sociais em fins do século XX. Vol. 4. Rio de Janeiro: Civilização Brasileira.

Fanelli, A. G., Gogna, M., e Jelin, E. (1989). El empleo del "cuello rosa” en La Argentina: El caso de um banco estatal. Documento Cedes, 24, (pp. 1-49).

Febraban (2014). II Censo da Diversidade. Recuperado de: https://cmsportal.febraban.org.br/Arquivos/ documentos/PDF/Censo\%20da\%20Diversidade\%202014\%20-\%20Apresentacao\%20Final\%20\%2003-11-14.pdf.

Ferreira, M. M., e Amado, J. (orgs) (1996). Usos e abusos da História Oral. Rio de Janeiro: Ed. FGV.

Geroleti, L. C. (2017). Moça Bradesco: Gênero, publicidade e carreira em um banco privado brasileiro (1976-1985). Anais do 13 Mundos de Mulheres e Fazendo Gênero 11: transformações, conexões, deslocamentos, Florianópolis/SC,Brasil Recuperado de: http://www.en.wwc2017.eventos.dype.com.br/ resources/anais/1503886993_ARQUIVO_MocaBradescoTextoCompletoFazendoGenero.pdf.

Geroleti, L. C. (2013). De normalistas a bancárias: A profissionalização das mulheres nos bancos (1960-1980) (Tese de Mestrado), Universidade do estado de Santa Catarina, Florianópolis/SC, Brasil. Recuperada de: http:// tede.udesc.br/handle/handle/1441.

Geroleti, L. C. (2010). Entre a "bela" e a "bancária": Memórias e representações femininas de mulheres bancárias (Trabalho de Conclusão de Curso de graduação), Universidade do Estado de Santa Catarina, Florianópolis/SC, Brasil. Recuperado de: http://sistemabu.udesc.br/pergamumweb/ vinculos/000000/00000000000F/00000FB7.pdf.

Gomes, A. C. (org.) (2004). Escrita de si, escrita da História. Rio de Janeiro: Ed. da FGV.

Hahner, J. E. (2011). Escolas mistas, escolas normais: A coeducação e a feminização do magistério no século XIX. Estudos Feministas, 19(2), 467-474.

Hahner, J. E. (2003). Emancipação do sexo feminino: a luta pelos direitos da mulher no Brasil: 1850-1940. Florianópolis: Mulheres.

Hollander, A. (1996). O sexo e as roupas: A evolução do traje moderno. Rio de Janeiro: Rocco.

Jinkings, N. (2002). Trabalho e resistência na fonte misteriosa: Os bancários no mundo da eletrônica e do dinheiro. Campinas/SP: Editora da Unicamp; São Paulo: Imprensa Oficial do Estado.

Karepovs, D. (1994). A história dos bancários: Lutas e conquistas (1923-1993). São Paulo: Sindicato dos bancários e financiários de São Paulo, Osasco e região.

Kossoy, B. (2001). Fotografia e História. São Paulo: Ateliê Editorial.

Lacerda, B., e Nasser, D. (1949). Normalista. [Gravada por N. G.]. Em Normalista/Quem será. Nova York: RCA Victor.

Lagrave, R. M. (1991). Uma emancipação sob tutela: educação e trabalho das mulheres no século XX. Em G. Duby, e M. Perrot [Orgs.], História das mulheres no ocidente: O século XX. Vol. 5. (pp.505-543). Porto: Edições Afrontamento.

Martini, S. M. S. (2011). Mulheres destinadas ao êxito: Trajetórias Escolares e Profissionais de Ex-alunas do Curso Cientifico do Colégio Coração de Jesus de Florianópolis (1949-1960) (Tese de Mestrado), Universidade do Estado de Santa Catarina, Florianópolis/SC, Brasil.

Meihy, J. C. S. B. (1996). Manual de história oral. São Paulo: Loyola. 
Mello, J. M. C., e Novais, F. A. (1998). Capitalismo tardio e sociabilidade moderna. Em Schwarcz (Org.), História da vida privada no Brasil: contrastes da intimidade contemporânea. Vol. 4. (pp. 559-658).São Paulo: Companhia das Letras.

Neckel, R. (2004). Pública vida intima: a sexualidade nas revistas femininas e masculinas (1969-1979) (Tese de Doutorado), Pontifícia Universidade Católica de São Paulo, São Paulo, Brasil. Recuperada de: https:// repositorio.ufsc.br/handle/123456789/111860.

Neihring, M. L. Q. (1981). Familia e feminismo: reflexóes sobre papéis femininos na imprensa para mulheres (Tese de Doutorado), Universidade de São Paulo, São Paulo, Brasil.

Nora, P. (1993). Entre memória e história: a problemática dos lugares. Projeto História, 10, 7-28.

Passerini, L. (2011). A memória entre política e emoção. São Paulo: Letra e Voz.

Perrot, M. (1989). Práticas da Memória Feminina. Revista Brasileira de História, 18(9), 9-18.

Perrot, M. (1988). Os excluidos da história:operários, mulheres e prisioneiros. Rio de Janeiro: Paz e Terra.

Petersen, A. T. (1999). Trabalhando no banco: trajetórias de mulheres gaúchas desde 1920 (Tese de Doutorado), Pontifícia Universidade Católica do Rio Grande do Sul, Porto Alegre, Brasil.

Portelli, A. (1997). O que faz a história oral diferente. Projeto História, 14, 25-39.

Puppim, A. (1994). Mulheres em cargos de comando. Em C. Bruschini e B. Sorj (orgs.), Novos olhares: mulheres e relaçôes de gênero no brasil (pp. 13-35). São Paulo: Marco Zero; Fundação Carlos Chagas.

Queirolo, G. (2014). O trabalho das mulheres na administração: A construção histórica da desigualdade Buenos Aires 1910-1950. Mouseion, 18,133-147. Recuperado de: https://revistas.unilasalle.edu.br/index.php/Mouseion/ article/view/1680

Reis, M. C. D. (1993). Tessituras de destinos: Mulher e educação. São Paulo: EDUC.

Schmitz, S. (1991). Bancos privados epúblicos em SC:A trajetória do BDE (contribuição à história bancária catarinense) (Tese de doutorado), Universidade de São Paulo, São Paulo, Brasil.

Scott, J. (1992). História das mulheres. Em P. Burke (org.), A escrita da história: novas perspectivas (pp. 63-96). São Paulo: UNESP.

Scott, J. (1990). Gênero: uma categoria útil de análise histórica. Educação e Realidade, 16, 73-99.

Segnini, L. (1998). Mulheres no trabalho bancário. São Paulo: Edusp.

Teive, G. M. G. (2008). "Uma vez Normalista sempre Normalista”. Cultura Escolar e Produção de um Habitus Pedagógico (Escola Normal Catarinense - 1911-1935). Florianópolis/SC: Ed. Insular.

Travesso, E. (2007). História e memória. Notas sobre um debate. Em M. Franco e F. Levin [Coords.], História reciente: perspectivas y desafios para un campo em Construción (pp 67-96). Buenos Aires: Paidós.

Woolf, V. (2012). Profissóes para mulheres e outros artigos feministas. Porto Alegre/RS: L\&PM.

\section{FONTES}

Arquivo Histórico dos bancários de Porto Alegre e região (AHPOA)

O Espelho. (1989). Edição Nacional. Brasília, ano VII, n.65, 28 jul.

\section{ENTREVISTAS ORAIS}

Fernanda (pseudônimo), 54 anos, divorciada, três filhos, admitida em 1973, trabalhou 17 anos no BESC. Entrevista concedida a Luciana Geroleti no dia 14/12/2009 na cidade de Florianópolis/SC, Brasil.

Leonora (pseudônimo), 62 anos, casada, duas filhas, trabalhou 24 anos em um banco público federal. Entrevista concedida a Luciana Carlos Geroleti no dia 07/08/2012 na cidade de Florianópolis/SC, Brasil.

Marta (pseudônimo), 62 anos, dois filhos, trabalhou 24 anos em um banco público federal. Entrevista concedida a Luciana Carlos Geroleti no dia 14/08/2012 na cidade de Florianópolis/SC, Brasil. 
Nair (pseudônimo), 67 anos, solteira, um filho, trabalhou 34 anos no Banco do Estado de Santa Catarina (BESC). Entrevista concedida a Luciana Carlos Geroleti no dia 25/03/2010 na cidade de Florianópolis/SC, Brasil.

Vera (pseudônimo), Casada, duas filhas, admitida em 1976, trabalhou 20 anos no BESC. Entrevista concedida a Luciana Carlos Geroleti no dia 11/03/2010 na cidade de Florianópolis/SC, Brasil.

O Estado. (1958). Florianópolis, 10 ag.

O Estado. (1962). Florianópolis, 13 jul.

O Estado. (1979). Florianópolis, 02 ag.

O Estado. (1979). Florianópolis, 03 ag.

MURAL. (1983 a 1987). Florianópolis: Informativo das Empresas do Sistema Codesc

\section{Notas}

1 A íntegra da Dissertação pode ser acessada pelo link http://tede.udesc.br/handle/handle/1441

2 O Trabalho de Conclusão de Curso de História está disponível no endereço http://sistemabu.udesc.br/pergamumweb/ vinculos/000000/00000000000F/00000FB7.pdf

3 Devido à existência de norma interna deste banco que impede de divulgar seu nome comercial, o mesmo será nomeado durante todo este artigo por "banco público federal".

4 O uso de seus depoimentos para fins acadêmicos foi autorizado pelas entrevistadas, conforme determina a metodologia.

5 Este debate pode ser observado nas obras de (Meihy, 1996); (Ferreira e Amado, 1996); (Gomes, 2004) e (Passerine, 2011).

6 As normalistas foram objeto de várias pesquisas de história da educação no Brasil (Teive, 2008); (Cunha, 2002). Foram retratadas também na literatura de Adolfo Caminha (Caminha, 1982), na música de Nelson Gonçalves (Lacerda e Nasser, 1949), além de peças de teatro e novelas. Sobre educação e femininização do magistério, ver (Reis, 1993) e (Hahner, 2003; 2011).

7 Nair (pseudônimo). Trabalhou 34 anos no Banco do Estado de Santa Catarina (BESC). Entrevista concedida a Luciana Carlos Geroleti no dia 25/03/2010, na cidade de Florianópolis/SC, Brasil.

8 Vera (pseudônimo). Trabalhou 20 anos no BESC. Entrevista concedida à Luciana Carlos Geroleti no dia 11/03/2010, na cidade de Florianópolis/SC, Brasil.

9 Fernanda (pseudônimo). Trabalhou 17 anos no BESC. Entrevista concedida à Luciana Geroleti no dia 14/12/2009, na cidade de Florianópolis/SC, Brasil.

10 Marta (pseudônimo). Trabalhou 24 anos em um banco público federal. Entrevista concedida a Luciana Carlos Geroleti no dia 14/08/2012, na cidade de Florianópolis/SC, Brasil.

11 Leonora (pseudônimo). Trabalhou 24 anos em um banco público federal. Entrevista concedida a Luciana Carlos Geroleti no dia 07/08/2012, na cidade de Florianópolis/SC, Brasil.

12 A abertura das faculdades de medicina às mulheres no Brasil só foi permitida a partir de 1879 com a Reforma Leôncio de Carvalho (Hahner, 2011).

13 A cidade de Florianópolis tem 95 \% de seu território localizado numa ilha. Nair morava no bairro Estreito, localizado no continente. Nesse período, a única ligação entre ilha e continente era a ponte Hercílio Luz, instalada em 1926, até hoje cartão postal da cidade.

14 Divisão escolar do ginásio vigente no período, sendo que apenas o curso científico dava acesso ao ensino superior (Dallabrida, 2007).

15 Tática é usada aqui no sentido atribuído por Michel de Certeau em “A invenção do Cotidiano”, como uma das muitas táticas que as mulheres "inventam" para sobreviver (Certeau, 2008).

16 A função das moças como recepcionistas dos bancos, como a famosa moça bradesco, é objeto de pesquisa em minha tese. Uma discussão inicial sobre o tema pode ser encontrada nos anais do evento do XI Encontro Internacional Fazendo Gênero (Geroleti, 2017).

17 Discuto os motivos desta proibição, bem como o contexto de aprovação da referida Lei, no primeiro capítulo da Dissertação de Mestrado (Geroleti, 2013).

18 Pesquisas de campo analisaram como o crescimento expressivo das mulheres no mercado de trabalho não teve ressonância nos cargos de topo das empresas brasileiras, mostrando o "teto de vidro" em diversas carreiras (Puppim, 1994); (Abreu, Hirata e Lombardi, 2016).

19 Deve ser ressaltado que, no Brasil, os bancários representam uma das categorias de trabalhadores mais organizadas desde a década de 1930, participando da criação das centrais sindicais em meados da década de 1980 (Canedo, 1986); (Karepovs, 
1994) e (Jinkings, 2002). Uma das questóes de minha tese de doutorado em andamento é analisar a participação das bancárias nas lutas sindicais da categoria e, especialmente, a luta pela igualdade entre homens e mulheres.

20 Conforme planilha elaborada pelo banco público federal, recebida por em 26 ag. 2012. Planilha disponível em meu arquivo pessoal.

21 Conforme tabelas de funcionários (Mural, 1987).

22 A calça comprida se firmou no guarda roupa feminino na década de 1960 (Hollander, 1996).A modificação dos costumes presentes na sociedade brasileira, ainda muito conservadora na década de 1960, chegava ao banco público de forma lenta e gradual.

23 Várias pesquisas realizadas sobre a década de 1970 e 1980 no Brasil mostram os discursos construídos pelas mídias sobre a mulher moderna no tocante ao trabalho, maternidade e sexualidade (Neckel, 2004) e (Nehring, 1981). 